\title{
Uso Pedagógico das Tecnologias Digitais: do Fazer ao Compreender
}

Ana Beatriz Michels Zaccaron, PPGEDU/UFRGS, biamichels@ yahoo.com.br Márcia Regina Souza de Souza, PPGEDU/UFRGS, mrs.geo@ig.com.br Lisiane Santos Massochini Amaro, PPGEDU/UFRGS, lisiane.lisiane@ gmail.com Fabiana Fattore Serres, PPGEDU/UFRGS, fabianaserres@gmail.com Rosane Aragón de Nevado, PPGEDU/UFRGS, rosane@edu.ufrgs.br

\begin{abstract}
Resumo
Este artigo propõe um estudo de caso de natureza qualitativa sobre o curso de graduação em Pedagogia à distância, ofertado pela Universidade Federal do Rio Grande do Sul. O objetivo deste artigo é a análise de portfólios de aprendizagem (blogs) de alunosprofessores enfocando o uso e compreensão das tecnologias, fundamentado na teoria Piagetiana do "Fazer e Compreender". Os dados foram coletados em uma amostra de vinte portfólios individuais de alunos-professores de dois polos do curso. A sistematização desses dados foi realizada com o apoio do software NVivo. Para a análise dos dados foram consideradas quatro categorias de análise: (1) Dificuldades iniciais no uso e compreensão das tecnologias; (2) Saber usar as tecnologias; (3) Compreender as tecnologias enquanto aluno; (4) Usar e compreender as tecnologias enquanto professor. Os resultados mostram uma evolução progressiva que parte de um saber fazer até alcançar níveis de compreensão do uso pedagógico das tecnologias digitais.
\end{abstract}

Palavras-chave: tecnologias digitais, $\mathrm{EaD}$, fazer e compreender, portfólios de aprendizagem.

\section{Pedagogical Use of Digital Technologies: from Make to the Understand}

\begin{abstract}
This article presents a case study of a qualitative nature about the distance undergraduate course of Pedagogy, offered by the Federal University of Rio Grande do $\mathrm{Sul}$. The purpose of this article is the analysis of learning portfolios (blog) of student teachers focusing on the use and understanding of digital technologies, based on Piagetian theory of "Make and Understand." The data were collected on a sample of twenty individual portfolios of student teachers from two poles of the course. The systematization of the data was performed with the assistance of NVivo software. For the analysis of the data were considered four categories of analysis: (1) initial difficulties on the use and understanding of technologies, (2) know to use the technologies, (3) understand the technologies as a student, (4) use and understand technologies as a teacher. The results show a progressive evolution that part of the know-how to achieve levels of understanding of the pedagogical use of digital technologies.
\end{abstract}

Keywords: digital technologies, EaD, make and understand, learning portfolios.

\section{Introdução}

O uso das tecnologias digitais na educação constitui um elemento inovador e transformador das práticas educacionais vigentes e potencializam o papel do professor. Este papel, que na metodologia tradicional de ensino era de um mero transmissor da informação, passa a ser de gestor dos recursos didáticos disponíveis, consultor no 
esclarecimento de dúvidas, guia na realização de projetos e mediador de debates e discussões (Coll e Monereo, 2010, p. 31).

Para que o professor compreenda o uso pedagógico das tecnologias digitais, a sua formação deve ser continuada, não se esgotando na conclusão de um curso de graduação, aliando a prática docente a um constante aperfeiçoamento (Nevado, Carvalho e Menezes in Nevado, Carvalho e Menezes (org.), 2007, p. 17).

Ainda de acordo com os autores supracitados, há inúmeras iniciativas que "estão traduzindo concretamente o compromisso de contribuir para a formação continuada dos professores brasileiros" (p. 17). Uma dessas iniciativas são os cursos de Pedagogia na modalidade à distância (EaD), e é justamente sobre esta égide que trata tal artigo. Nosso foco é o PEAD - curso de Pedagogia da Universidade Federal do Rio Grande do Sul na modalidade à distância.

Tendo em vista a proposta pedagógica do PEAD, voltada para a construção de conhecimento do aluno sobre o seu próprio modelo em ação, com o auxílio das tecnologias digitais, neste artigo discutimos como ocorreram: (1) o processo de evolução da apropriação e compreensão tecnológica enquanto alunos e (2) a incorporação destas tecnologias digitais nas práticas pedagógicas enquanto professores.

Nas seções seguintes apresentamos uma análise de portfólios de aprendizagem (blogs) de alunos-professores enfocando o uso e compreensão das tecnologias, enquanto alunos e professores. Na primeira seção apresentamos o curso do PEAD, que foi utilizado como estudo de caso para esta pesquisa. Na segunda seção discorremos acerca da teoria Piagetiana do "Fazer e Compreender", na qual esta análise está fundamentada. Na seção seguinte abordamos o uso do blog enquanto portfólio de aprendizagem. Na seqüência justificamos a escolha do curso do PEAD e da análise da ferramenta blog como espaço destinado à coleta de dados. Descrevemos como foi feita a coleta e a análise de dados, discutindo, posteriormente, os resultados da pesquisa. $\mathrm{Na}$ última seção apresentamos as considerações finais acerca do estudo.

\section{Sobre o PEAD}

O PEAD, realizado no período de 2006 a 2010, buscou superar a dicotomia existente nos modelos tradicionais de cursos voltados para a formação de professores, que apenas teorizam sobre transformações nas práticas educativas, não oportunizando a vivência de tais transformações no ambiente escolar. Desta forma, a proposta pedagógica do PEAD, que está baseada na interdisciplinaridade, busca a construção do conhecimento do aluno sobre o seu próprio modelo em ação a partir dos usos de metodologias interativas e da internet para desenvolver e acompanhar as aprendizagens (Nevado, Carvalho e Menezes, 2007, p. 18).

Na perspectiva de formação continuada e em serviço, os estudos no PEAD estão vinculados à experiência de vida profissional, onde o aluno-professor conserva tudo que lhe parece válido e busca transformar a sua prática de modo significativo, incorporando a inovação no seu trabalho (Nevado, Carvalho e Menezes in Valente e Bustamante, 2009, p. 86).

Os materiais pedagógicos utilizados no curso foram pensados e desenvolvidos a fim de proporcionar aprendizagem mediada pelas tecnologias digitais. Assim, eles acabaram por dinamizar a vivência tecnológica nos alunos-professores. Tal vivência resultou na incorporação das tecnologias digitais, seja de modo consciente ou não, às práticas pedagógicas (enquanto alunos-professores e enquanto professores com os seus alunos). 


\section{Perspectiva teórica: o fazer e compreender}

Segundo Piaget (1978, p.176), "fazer é compreender em ação uma dada situação" para atingir os fins propostos. E "compreender é conseguir dominar, em pensamento, as mesmas situações até poder resolver os problemas por elas levantados, em relação ao por que e ao como das ligações constatadas e, por outro lado, utilizadas na ação". Quando falamos em fazer, "compreender em ação", estamos nos referindo às coordenações das ações. E quando falamos em compreender, "conseguir dominar em pensamento", estamos nos referindo às coordenações conceituais lógico-matemáticas.

Mas como a coordenação de ações pode levar ao conhecimento? Em outras palavras, queremos compreender como o pensamento do sujeito pode passar de uma situação onde quase tudo é sucessivo e causal à outra, que permite estabelecer relações atemporais entre os possíveis e o necessário. Acreditamos que tal resposta encontra-se em Piaget (1978), quando este nos diz que a razão desses poderes cognitivos da ação está em sua causalidade orgânica, com capacidades de organização e de autoorganização.

Chiarottino (1988) diz que, para compreendermos esta causalidade orgânica, precisamos voltar à questão da assimilação e da acomodação na construção de estruturas mentais, entendidas estas como um processo de construções progressivas em que o meio provoca transformações internas no organismo (em nível neurológico), graças às quais este mesmo organismo se torna apto a receber novos estímulos que, ou são assimilados inteiramente, ou provocam novas transformações internas, que por sua vez, permitirão a captação de novos estímulos e assim por diante. Dado este movimento, crescente e progressivo, o ser humano vai construindo, em nível endógeno, as estruturas mentais específicas para o ato de conhecer e assim se tornando capaz de estabelecer relações (inicialmente no campo da ação e posteriormente, da representação).

De acordo com Piaget (1978), compreender consiste em isolar a razão das coisas, enquanto fazer é somente utilizá-las com sucesso. A ação é uma condição preliminar da compreensão. Mas esta ação é ultrapassada pela compreensão, visto que o sujeito atinge um saber que precede a ação e pode, portanto, abster-se dela.

Em suma, cremos que a compreensão ou busca das razões tem de ultrapassar o êxito das ações e enriquecer o pensamento, uma vez que o mundo das razões se amplia sobre os possíveis, indo além do real. Assim, com vistas a aproximar a teoria ao bricoleur tecnológico do PEAD, escolhemos uma ferramenta, o blog, como fonte para análise e discussão dos dados estudados neste trabalho.

\section{Uso do blog como portfólio de aprendizagem}

Com o advento da web 2.0 os modelos pedagógicos vêm assumindo outras formas, mais abertas e flexíveis. E isto tem impactado nas formas de ensinar e aprender, principalmente em se tratando da $\mathrm{EaD}$ em questão, voltada para um público tão específico: os alunos-professores, imigrantes digitais. Ou seja, tratava-se de uma clientela que necessitava reconstruir seus conhecimentos, habilidades e atitudes para lidar com os seus próprios alunos, nativos digitais. Nessa perspectiva, algumas ferramentas tecnológicas foram incorporadas ao PEAD, entre elas, o blog.

Gomes (2005) afirma que um blog pode ser utilizado como recurso e estratégia pedagógica, sendo visto como espaço de acesso à informação especializada e de disponibilização de informação por parte do professor, podendo assumir a forma de: (1) portfólio digital; (2) espaço de intercâmbio e colaboração; (3) espaço de dabate e (4) espaço de integração.

De acordo com a análise realizada em um determinado conjunto de blogs, para a redação deste artigo, entendemos que no contexto do PEAD a ferramenta blog tomou a 
forma de portfólio digital de aprendizagem. Ou seja, a configuração representativa deste recurso tornou-se bastante peculiar, pois, fundiram-se as quatro possibilidades apontadas por Gomes (2005).

Apresentamos a seguir a análise e discussão dos dados estudados à luz da teoria Piagetiana, conforme citamos outrora.

\section{Coleta e análise dos dados}

A pesquisa foi desenvolvida por meio de uma abordagem qualitativa, desenvolvida através de um estudo de caso sobre a percepção dos alunos do PEAD a respeito do uso das tecnologias em suas vivências enquanto discentes (alunosprofessores) e docentes (professores com os seus alunos).

Tendo em vista que a abordagem qualitativa se preocupa mais com o processo do que com o produto, sendo que o foco principal do pesquisador é o significado que as pessoas dão às coisas e à sua vida (Ludke e André, 1986), os dados apresentados foram extraídos dos blogs individuais dos alunos-professores. Estes blogs foram utilizados ao longo do PEAD, como portfólios de aprendizagem, e permitem a visualização da produção escrita dos alunas que dão "voz" às suas ideias, interesses, pensamentos e angústias.

Para coletar os dados, recorremos às postagens do último ano do curso, 2010, que traziam reflexões do início do curso acerca das dificuldades iniciais em relação ao uso das tecnologias digitais e de como os alunos-professores, no decorrer do curso, apropriaram-se destas tecnologias e incorporaram-nas em suas práticas pedagógicas.

A amostra foi definida considerando o critério de saturação teórica ${ }^{[1]}$. Buscando uma garantia quanto a possíveis fatores de subjetividade excessiva, a amostra não foi fechada antes de ser atingido $20 \%$ dos sujeitos dentro do universo estudado. Foram incluídos na amostra vinte sujeitos de dois polos do curso.

Para análise dessa coleta, utilizamos o software $\mathrm{NVivo}^{[2]}$, que "trabalha com o conceito de projeto. As fontes de informação do projeto, assim como os dados gerados durante o processo de análise, como categorias de informações, são armazenadas em um banco de dados" (Bringer et al., 2006 citado por Lage, 2011).

A utilização do NVivo auxiliou-nos no encadeamento entre os dados e o referencial teórico. O uso deste também ajudou na procura de ocorrências de termos e expressões específicas, evitando tarefas repetitivas, porém não substituiu a leitura e reflexão por nós realizados.

Gibbs (2009, p.159) enfatiza que em cada resultado de uma operação realizada pelo software "precisa de você, do humano, para fazer uma leitura do que foi encontrado e avaliar seu significado e sua relevância para os conceitos relevantes". O uso deste tipo de programa garante que o pesquisador encontre dados que poderiam ter ficado para trás, mas não garante que sejam encontrados apenas termos relevantes, cabendo ao pesquisador fazer esta filtragem e considerar o que realmente interessa à pesquisa.

Após a análise das postagens nos blogs individuais dos sujeitos da pesquisa, juntamente com o referencial teórico, os dados foram organizados em quatro categorias, como mostra a Tabela 1. 
Tabela1: Descrição das categorias da pesquisa.

\begin{tabular}{|l|l|}
\hline \multicolumn{1}{|c|}{ Categoria } & \multicolumn{1}{c|}{ Definição } \\
\hline $\begin{array}{l}\text { 1. Dificuldades iniciais no uso e } \\
\text { compreensão das tecnologias }\end{array}$ & $\begin{array}{l}\text { Dificuldades iniciais em relação ao uso das tecnologias digitais } \\
\text { enquanto alunos do curso. }\end{array}$ \\
\hline 2. Saber usar as tecnologias & $\begin{array}{l}\text { Apropriação de ferramentas tecnológicas básicas enquanto } \\
\text { alunos do curso. }\end{array}$ \\
\hline $\begin{array}{l}\text { 3. Compreender as tecnologias } \\
\text { enquanto aluno }\end{array}$ & $\begin{array}{l}\text { Processo de compreensão do uso das tecnologias digitais na } \\
\text { ação desempenhada enquanto alunos do curso. }\end{array}$ \\
\hline $\begin{array}{l}\text { 4. Usar e compreender as tecnologias } \\
\text { enquanto professor }\end{array}$ & $\begin{array}{l}\text { Processo de compreensão e incorporação das tecnologias } \\
\text { digitais, na prática pedagógica enquanto professores. }\end{array}$ \\
\hline
\end{tabular}

Na Tabela 2, as referências encontradas em cada categoria são quantificadas. Antes mesmo de analisar os dados, é possível perceber que, embora os alunos tivessem apresentado dificuldades inicias quanto ao uso das tecnologias digitais, eles conseguiram compreender o seu uso e as incorporar em suas práticas pedagógicas.

Tabela 2: Total de referências encontradas nos blogs relacionadas às categorias da pesquisa.

\begin{tabular}{|c|c|}
\hline Categoria & Referências \\
\hline 1. Dificuldades iniciais no uso e compreensão das tecnologias & 24 \\
\hline 2. Saber usar as tecnologias & 31 \\
\hline 3. Compreender as tecnologias enquanto aluno & 60 \\
\hline 4. Usar e compreender as tecnologias enquanto professor & 67 \\
\hline
\end{tabular}

Trazemos, a seguir, algumas postagens extraídas dos blogs, separadas nas quatro categorias e que mostram o processo de evolução do fazer e compreender dos alunosprofessores em relação à apropriação e uso das tecnologias digitais.

\section{Categoria 1: Dificuldades iniciais no uso e compreensão das tecnologias}

Conforme definido na Tabela 1, esta categoria está relacionada com as dificuldades iniciais dos alunos em relação ao uso das tecnologias digitais. Dentre os vinte blogs analisados, em doze há referências sobre estas dificuldades, que mostram que as tecnologias ou nunca fizeram parte do cotidiano dos alunos, sendo vistas como um "bicho de sete cabeças", ou, se em algum momento já fizeram, não lembravam como se fazia, não ocorrendo uma tomada de consciência. Eis algumas postagens que mostram que os alunos estavam inseguros em relação ao desconhecido, pois nunca haviam tido contato com as tecnologias digitais.

Aluno A1: Nossa... quanta coisa vimos em quatro anos. Lembro-me que o início do curso foi meio caótico. Muitas colegas acabaram por desistir, pois éramos verdadeiras analfabetas digitais. Nunca tinha ouvido falar em pbwiki, blog, postagens, aula à distância? mas como???

Um posicionamento semelhante pode ser visto na postagem do aluno A2: 
Aluno A2: Muitas vezes chorei por sentir-me impotente diante de um objeto tão pequeno e tão misterioso. Muitas vezes passei a noite toda trabalhando em um determinado tema para chegar à madrugada, ao final do trabalho, vencida pelo cansaço e num "clik" fechar a tela sem salvar e o esforço e dedicação de horas sumir em menos de um segundo.

Vejamos, para comparação, a postagem do aluno A3, que já havia utilizado as tecnologias digitais antes de ingressar no curso, mas não lembrava como trabalhar com uma certa ferramenta.

Aluno A3: Olá professores, tutores e colegas, hoje gostaria de falar um pouco sobre minhas aprendizagens desta semana, na minha primeira postagem comentei que a atividade I era muito difícil para mim pois não lembrava de como se fazia um pbworks.

Através dessas postagens verificamos que no início do curso, quando os alunos foram colocados frente a situações que não faziam parte dos seus cotidianos, precisando interagir com as tecnologias digitais, eles não conceituaram suas ações, não havendo a construção de conhecimento. Mesmo que os alunos agissem sobre o objeto de conhecimento, neste caso as tecnologias digitais, eles não conseguiam assimilá-lo, não dando significação ao mesmo. Desta forma o objeto não era estruturado ou, se era estruturado, não havia alcançado necessariamente a estruturação lógico-matemática (Chiarottino, 1988, p. 4-5).

As dificuldades iniciais, ocasionadas a partir das interações entre os alunos e as tecnologias digitais, fizeram com que os alunos entrassem em desequilíbrio, pois precisavam inserir o objeto desconhecido nas suas estruturas. Mas será que eles conseguiram assimilar as tecnologias? A resposta para esta pergunta é apresentada na análise dos dados das próximas categorias.

\section{Categoria 2: Saber usar as tecnologias}

Esta categoria está relacionada à apropriação das ferramentas tecnológicas básicas dos alunos durante o curso. Após um período inicial de dificuldades com o uso das tecnologias digitais, os alunos passaram a interagir, cada vez mais, com as tecnologias, alcançando um patamar de autonomia nas suas ações. Ou seja, conseguiram saber usar as tecnologias digitais. Este saber usar as tecnologias pode ser visto nas postagens dos alunos abaixo.

Aluno A4: Durante o quarto semestre tivemos o desafio de realizar um plano individual de estudos, onde pude verificar o que eu estava precisando aprender. Esta oportunidade fez com que eu me dedicasse à realização de algumas atividades, as quais eram simples, mas que eu desconhecia. Aprendi a utilizar o pen drive, gravar cd de músicas, criar gráficos e planilhas e não tinha MSN, então fiz um pra mim. Realizar esta atividade fez eu aprimorar meus conhecimentos tecnológicos, coisas que eu deixava passar, mas que hoje me auxiliam muito e que com certeza fariam muita falta se não tivesse aprendido, além de que não preciso mais do auxílio de outros para a realização destas atividades.

Aluno A5: (...) para conseguir realizar as atividades propostas tive que me apropriar das diversas ferramentas tecnológicas. Precisei estabelecer redes de aprendizagens, isto é, busquei ajuda de parentes, amigos, colegas e tutores. Aos poucos fui adquirindo 
o domínio das tecnologias e o que antes parecia um "bicho de sete cabeças", passou a fazer parte da minha vida pessoal, profissional e de estudante.

As postagens relacionadas à categoria 2 mostram que os alunos se sentiram desafiados em relação ao "desconhecido" e, aos poucos, foram adquirindo domínio sobre as ferramentas básicas relacionadas às tecnologias digitais. Porém, neste estágio, os alunos aprenderam a usar as ferramentas e, mesmo fazendo parte de suas vidas enquanto alunos, não conseguiram compreender em pensamento, pois, como foi apresentado anteriormente (Piaget, 1978, p. 176), sabiam apenas fazer, ou seja, só compreenderam em ação.

\section{Categoria 3: Compreender as tecnologias enquanto aluno}

O saber usar as tecnologias digitais é um instrumento para se ter êxito em uma dada ação, ou seja, é usá-las com sucesso. Porém, na realização de novas ações, é possível se obter êxito ou fracasso e, em função da resistência do objeto, o sujeito passa a refletir sobre suas ações, podendo iniciar um processo de compreensão, ou seja, dominar em pensamento o uso das tecnologias digitais, conseguindo isolar a razão das coisas (Piaget, 1978, p. 179), conforme foi mostrado anteriormente.

A compreensão dos alunos em relação ao uso das tecnologias digitais pode ser percebida na análise desta categoria, como mostram as postagens abaixo.

Aluno A6: Tendo em vista a minha trajetória dentro do PEAD, minhas construções e também dificuldades enfrentadas até aqui, espero neste semestre, além de obter novos conhecimentos, que com certeza me ajudarão a melhorar, ou até mesmo mudar, se necessário for, minha prática pedagógica, tenho como maior desafio e propósito, aprender com qualidade. O que significa isso? Para mim significa não somente realizar as leituras e posteriores atividades relacionadas é, principalmente, mudar minhas concepções sobre o Ensino à distância, estar mais conectada e atuante no que diz. respeito à aprendizagem colaborativa, participar sistematicamente de fóruns, trocar experiências sobre práticas em sala de aula, debater, discutir, concordar, discordar.

Aluno A4: A tecnologia não fez só com que inovássemos com os alunos, como possibilitou um leque de interações entre o grupo, tanto nos fóruns, como nos blogs, ferramentas estas que foram essenciais para a troca de saberes. Os fóruns contribuíram muito para conhecer a realidade de muitas colegas e a construção do portfólio de aprendizagens me fez refletir e analisar a prática pedagógica e principalmente melhorar minha escrita. Relendo as postagens, percebi que estão mais consistentes e não breve relatos, como as primeiras.

Nestas postagens, é possível visualizar uma compreensão do uso das tecnologias digitais nas atividades propostas pelo curso. Os alunos realizaram as atividades, pois conseguiram conceituar as ações, possibilitando que, em presença de uma dada situação, eles tivessem um plano de utilização imediata (Piaget, 1978, p. 174).

Eles afirmaram que não queriam apenas realizar as atividades, mas queriam mudar suas concepções sobre a $\mathrm{EaD}$, no que diz respeito à aprendizagem colaborativa. Desta forma, os alunos compreenderam não só o uso das tecnologias digitais, mas como poderiam ser usadas pedagogicamente. Essa compreensão serviu de base para a construção de uma prática pedagógica mais integrada ao mundo digital, como mostra a categoria 4. 


\section{Categoria 4: Usar e compreender as tecnologias enquanto professor}

Nesta categoria os alunos passaram a compreender e incorporar as tecnologias digitais em suas práticas pedagógicas, enquanto professores. A vivência adquirida no curso fez com que eles pudessem utilizar, em sala de aula, as atividades realizadas no curso. E em muitos casos, recriá-las, o que corroborou no domínio das atividades em pensamento. As postagens abaixo reforçam esta afirmação.

Aluno A7: (...) É o que observei ao longo do meu estágio com o projeto de trabalho Caderno Virtual, desenvolvido com a turma 43. A qualidade do emocionar da turma foi mudando no decorrer do trabalho, pois foi construída uma rede de conversação, onde as diferentes verdades se uniram, numa linguagem respeitosa de troca, a fim de atingirmos juntos um objeto comum, combinando ações individuais para que juntas formassem um todo. A formação de blogs individuais para a construção das aprendizagens, que embora sejam únicas para cada um, pertence a um conjunto, o conjunto das aprendizagens da turma 43.

Aluno A8: Minha prática pedagógica possui aulas com atividades mais inovadoras, sinto-me incluída assim como meus alunos no mundo digital, apresentando projetos de uso do Laboratório de Informática, não somente de pesquisa e jogos, mas um oportunizar a construção do conhecimento pelo próprio educando. Acreditando que o uso da informática, tendo objetivos específicos, potencializa o trabalho do professor e motiva os alunos, requerendo conhecimento e, acima de tudo, dedicação.

As postagens relacionadas à categoria 4 mostraram que os alunos incorporaram as tecnologias digitais nas suas práticas pedagógicas, a partir das aprendizagens adquiridas no curso, e compreenderam a sua importância na construção do conhecimento tanto deles como professores, quanto de seus alunos.

\section{Considerações Finais}

Neste trabalho analisamos os blogs de alunos-professores do curso do PEAD e enfocamos o uso e compreensão das tecnologias digitais, fundamentado na teoria Piagetiana do "Fazer e Compreender".

Percebemos, ao final da análise dos recortes extraídos dos blogs, que os alunosprofessores do PEAD, mesmo apresentando algumas dificuldades iniciais em relação ao uso das tecnologias digitais, conseguiram superá-las. Tendo em vista esta superação, percebemos que estes compreenderam a essência do saber usar tal ferramental, tanto enquanto alunos como enquanto professores em sua práxis cotidiana.

Ou seja, houve uma evolução progressiva que partiu de um saber fazer, onde os alunos-professores se apropriaram das tecnologias digitais, até alcançar níveis de compreensão do uso pedagógico dessas tecnologias. Desta forma, os alunosprofessores, além de compreenderem em ação, conseguiram dominar as tecnologias digitais em pensamento. A partir do momento que eles conseguiram conceituar suas ações, foi possível tecer um plano de utilização imediata. Assim, cremos que neste nível, houve um "aumento do poder de coordenação, já imanente à ação, e isso sem que o indivíduo estabelecesse fronteiras entre a sua prática ("o que fazer para conseguir") e o sistema de seus conceitos ("porque as coisas se passam desta maneira")" (Piaget, 1978, p. 174). 


\section{Notas}

${ }^{[1]}$ Segundo Fontanella et al (2011), o fechamento amostral, por saturação teórica, é definido como a suspensão de inclusão de novos participantes quando os dados obtidos passam a apresentar, na avaliação do pesquisador, redundância ou repetição não sendo considerado relevante persistir na coleta de dados já que não são encontradas novas contribuições significativas para o aperfeiçoamento da reflexão teórica fundamentada nos dados que estão sendo coletados.

${ }^{[2]}$ Para informações adicionais sobre as funcionalidades e as formas de aquisição do NVivo, acesse http://www.qsrinternacional.com.

\section{Referências Bibliográficas}

BRINGER, J. D.; JOHNSTON, L.H.; BRACKNRIDGE, C.H. Using computer-assisted qualitative data analysis software to develop a grounded theory project. Field Methods, v. 18. n. 3, p. 245-266, 2006. In: LAGE, M. C. Utilização do software NVivo em uma pesquisa qualitativa: uma experiência em EaD. ETD - Educação Temática Digital, Campinas, v. 12, p. 198-226, 2011.

CHARCZUK, S. B.; ZIEDE, M. L. Blogs como Portfólios de Aprendizagem: a Construção de Conhecimentos a partir da Interação entre Tutores e Alunos. RENOTERevista Novas Tecnologias na Educação, Porto Alegre, v. 8, n. 1, p. 1-8, 2010.

CHIAROTtinO, Z. R. Psicologia e epistemologia genética de Jean Piaget. São Paulo: EPU, 1988. 87 p.

COLL, C.; MONEREO, C.. Psicologia da Educação Virtual: Aprender e ensinar com as tecnologias da informação e da comunicação. Porto Alegre: Artmed, 2010. $365 \mathrm{p}$.

FONTANELLA, Bruno José Barcellos; LUCHESI, Bruna Moretti; SAIDEL, Giovana Borges. Amostragem em pesquisas qualitativas: proposta de procedimentos para constatar saturação teórica. Cad. Saúde Pública, Rio de Janeiro, 27(2):389-394, fev, 2011.

GIBBS, Graham. Análise de dados qualitativos. Artmed: Porto Alegre, 2009. 198 p.

GOMES, M. J. Blogs: um recurso e uma estratégia pedagógica. In: MENDES, A.; PEREIRA, I.; COSTA, R. (editores). Actas do VII Simpósio Internacional de Informática educativa. Leiria: Escola Superior de Educação de Leiria, p. 311-315, 2005.

LUDKE, M. ANDRÉ, M. Pesquisa em educação: abordagens qualitativas. São Paulo, Editora Pedagógica e Universitária, 1986. 99 p.

NEVADO, R. A.; CARVALHO, M. J.; MENEZES, C. S. Metareflexão e a construção da (trans)formação permanente: estudo no âmbito de um curso de pedagogia a distância. In: VALENTE, J. A.; BUSTAMANTE, S. V. (organizadores). Educação a distância: prática e formação do profissional reflexivo. São Paulo: Avercamp, 2009, p. 83-108.

NEVADO, R. A.; CARVALHO, M. J.; MENEZES, C. S. Educação a distância mediada pela internet: uma abordagem interdisciplinar na formação de professores em serviço. 
In: NEVADO, R. A.; CARVALHO, M. J.; MENEZES, C. S. (organizadores).Aprendizagem em rede na educação a distância: estudos e recursos para formação de professores. Porto Alegre: Ricardo Lenz, 2007, p. 17-33.

PIAGET, Jean. Fazer e compreender. São Paulo: Melhoramentos, 1978. 186 p. 